\title{
Rare Cause of Nuchal Pain: Calcification of the Alar Ligament
}

NAOHO TAKIZAWA, MD, Department of Rheumatology, Chubu Rosai Hospital, Nagoya, Japan; ATSUSHI NOMURA, MD, Department of Rheumatology, Chubu Rosai Hospital, Nagoya, Japan; YOSHIRO FUJITA, MD, Department of Rheumatology, Chubu Rosai Hospital, Nagoya, Japan. Address correspondence to Dr. Naoho Takizawa, Department of Rheumatology, Chubu Rosai Hospital, 1-10-6 Komei, Minato-ku, Nagoya 455-8530, Japan. E-mail: ttkkzzww5959@gmail.com. J Rheumatol 2016;43:177-8; doi:10.3899/jrheum.150905

Calcification of the alar ligament is a rare condition, which usually develops in the elderly and tends to occur following traumatic injury or as a consequence of inflammatory disease. In crowned dens syndrome, calcium pyrophosphate dehydrate crystals deposit on the atlantoaxial joint.

A 38-year-old woman with no history of traumatic injury presented with acute-onset neck pain. The patient was diagnosed with rheumatoid arthritis (RA) and treated with 20 $\mathrm{mg}$ of prednisolone per day. She was also prescribed $300 \mathrm{mg}$ of isoniazid per day for latent tuberculosis. On physical examination, we found that she could not move her neck voluntarily and strong pain was induced by passive neck motion in any direction. C-reactive protein was elevated $(0.72$ $\mathrm{mg} / \mathrm{dl}$, normal $<0.3)$. Crowned dens syndrome and cervical epidural abscess were suspected, so cervical computed tomography (CT) and magnetic resonance imaging were checked. They revealed calcification of the left alar ligament of the cervical spine.

Calcification usually develops in the elderly and typically occurs following traumatic injury or as a result of inflammatory disease. Calcium pyrophosphate dehydrate crystals deposit on the atlantoaxial joint in crowned dens syndrome. Calcifications are seen around the top and sides of the odontoid process in the CT scan. In this case and unlike crowned dens syndrome, calcifications were seen along the alar ligaments focally.

Calcification has been reported in cases of young patients with nuchal pain induced by inflammation of alar ligament ${ }^{1,2}$.

A patient with RA has been reported as having this condition, but the association between RA and calcification of the alar ligament has not been made ${ }^{3}$. The patient's neck pain was resolved after 2 weeks of continued treatment for RA.

\section{REFERENCES}

1. Che Mohamed SK, Abd Aziz A. Calcification of the alar ligament mimics fracture of the craniovertebral junction (CVJ): an incidental finding from computerised tomography of the cervical spine following trauma. Malays J Med Sci 2009;16:69-72.

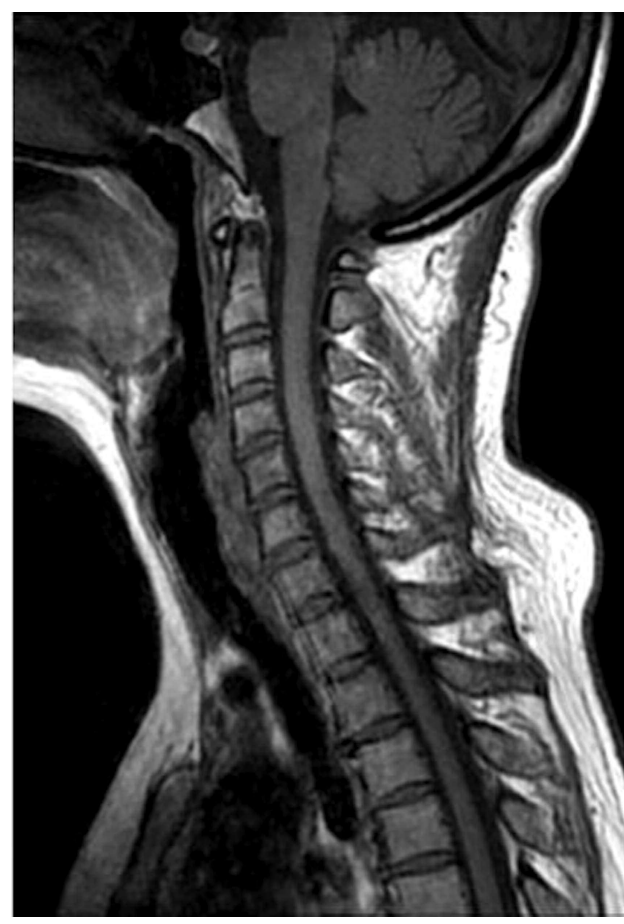

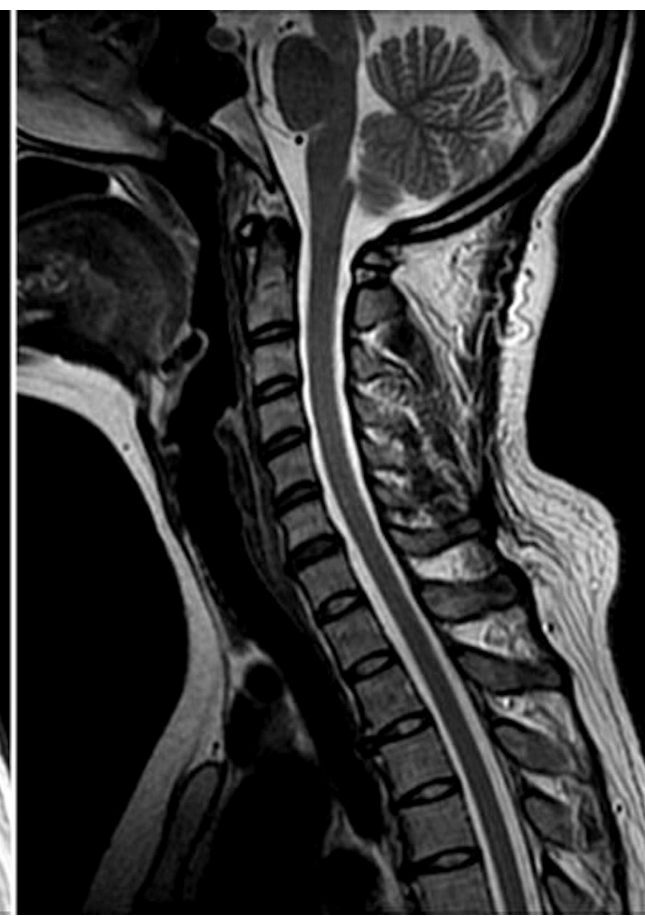

Figure 1. T1-weighted MRI sequences of cervical spine (left) and T2-weighted image of cervical spine (right) show neither atlantoaxial subluxation nor epidural abscess. MRI: magnetic resonance imaging.

Personal non-commercial use only. The Journal of Rheumatology Copyright @ 2016 . All rights reserved. 


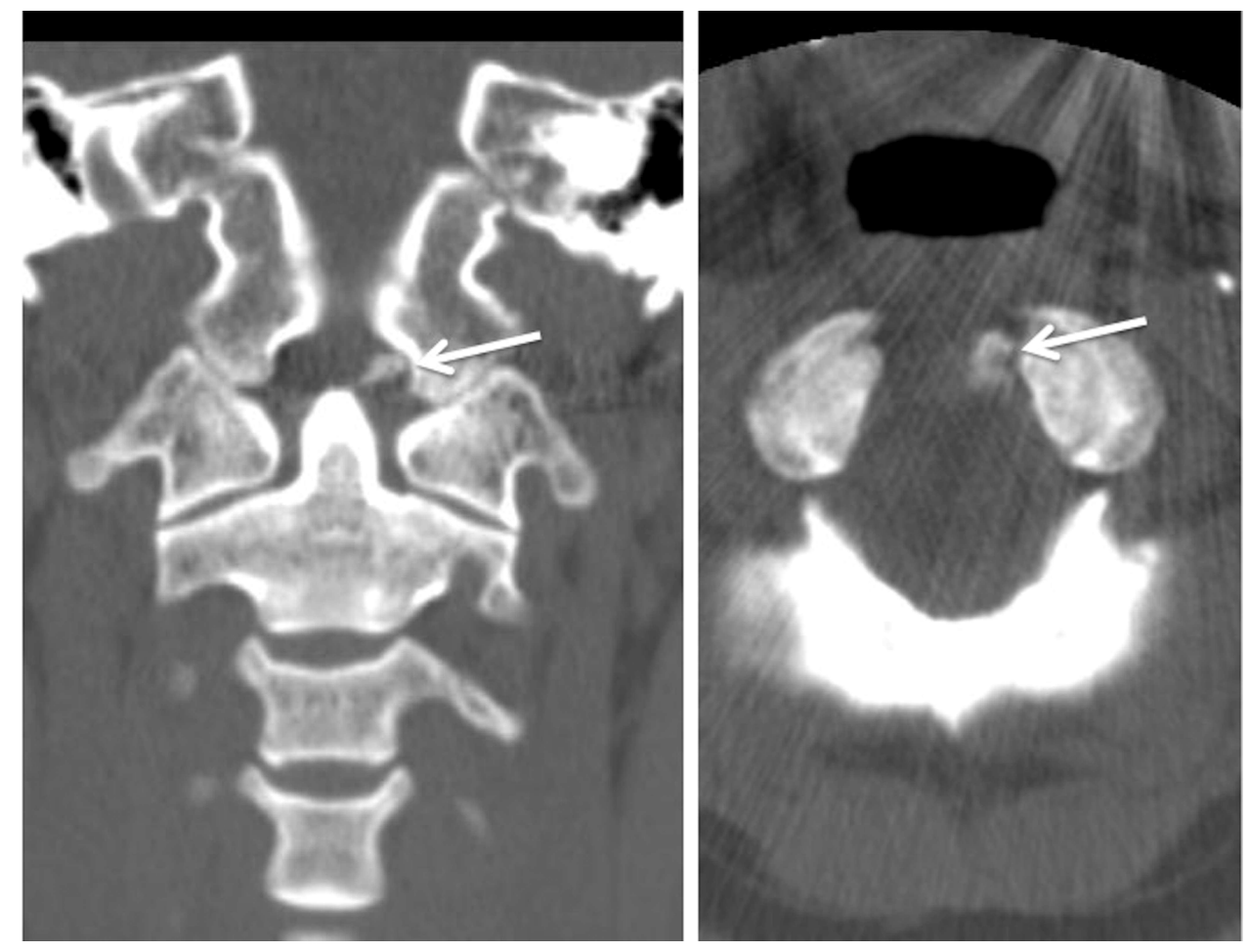

Figure 2. Coronal (left) and axial (right) images of cervical CT show calcification of the left alar ligament (arrows). CT: computed tomography.

2. Kobayashi Y, Mochida J, Saito I, Matui S, Toh E. Calcification of the alar ligament of the cervical spine: imaging findings and clinical course. Skeletal Radiol 2001;30:295-7.
3. Soubai RB, Tahiri L, Abourazzak FZ, Tizniti S, Harzy T.

Calcification of the alar ligament of the cervical spine in a patient with rheumatoid arthritis. Pan Afr Med J 2012;13:41. 